\title{
Banco de sementes de aveia preta no solo sob dois sistemas de manejo
}

\author{
Soil seed bank of black oat in two management systems
}

\section{Marcos Paulo Ludwig ${ }^{\mathrm{I}}$ Manoel de Souza Maia' ${ }^{\mathrm{II}}$ Marciabela Fernandes Corrêa ${ }^{\mathrm{III}}$}

\section{RESUMO}

\begin{abstract}
As sementes de aveia preta (Avena strigosa Schreb.) possuem a capacidade de permanecer viáveis no solo de um ano de cultivo para outro. Dessa forma, o objetivo do trabalho foi avaliar o número de sementes de aveia preta resultantes de dois sistemas de manejo (colheita e ressemeadura natural), que poderão formar o banco de sementes do solo. Os ensaios foram realizados no município de Jari - RS, em uma área cultivada sob o sistema de "plantio direto". Foram coletadas 50 amostras em cada sistema de manejo, com um espaçamento de $10 \times 20 \mathrm{~m}$, utilizando um amostrador de diâmetro de $0,05 \mathrm{~m}$ e uma profundidade de $0,1 \mathrm{~m}$. O levantamento do número de sementes e da emergência das plântulas foi realizado no Laboratório Didático da Faculdade de Agronomia Eliseu Maciel (UFPel). Constatou-se que a colheita e a ressemeadura natural possibilitam a presença de sementes no solo por área, em quantidades superiores à indicada para a semeadura. Com a colheita, a área fica heterogênea em número de sementes no solo e em plântulas emergidas. A ressemeadura natural resulta em uma grande quantidade de sementes no solo e formação de plântulas.
\end{abstract}

Palavras-chave: Avena strigosa Schreb, espécie forrageira, ressemeadura natural, integração lavourapecuária.

\section{ABSTRACT}

The black oat (Avena strigosa Schreb.) seeds are able to remain alive in soil from a culture to another. The objective of this study was to evaluate the number of black oat seeds resulting from two management, harvesting, and natural reseeding, which could form the seed bank of soil. The experiments were conducted in Jari-RS, Brazil, the cultivation system is "No Tillage". Were collected 50 samples in each management, at a spacing of $10 \mathrm{~m} \times 20 \mathrm{~m}$, using a sampler diameter of $0.05 \mathrm{~m}$ and depth of $0.1 \mathrm{~m}$. The evaluation of the number of seeds and seedling emergence was accomplish at the Laboratory of Seeds Analysis of the Faculdade de Agronomia "Eliseu Maciel" (UFPEL). It was found that both as the crop as the natural seeding allow large quantities of seeds in the soil for the upper area suitable for planting. The harvest area is heterogeneous in the number of seeds in soil and plants in the area. The natural seeding results in a large amount of seed in soil and seedling.

Key words: Avena strigosa Schreb, forage specie, natural seeding, integrated crop-livestock.

\section{INTRODUÇÃO}

A aveia preta (Avena strigosa Schreb.) tem um papel importante no sistema de produção de grãos e na integração lavoura-pecuária do Sul do Brasil, pela sua capacidade de formar pastagem e cobertura do solo, além de ser um importante cereal de inverno, com crescente demanda para uso, tanto de forma isolada como consorciada para cobertura do solo ou para forragem (MENEZES et al., 2007). A espécie, cultivada como forrageira, disponibiliza alimento aos animais nas épocas de menor oferta pelas pastagens naturais. Ela também pode ser usada como cobertura verde/morta de solo, evitando as perdas por erosão causadas pela chuva (COMISSÃO BRASILEIRA DE PESQUISA DE AVEIA, 2006).

'Instituto Federal de Educação, Ciência e Tecnologia do Rio Grande do Sul, Campus Ibirubá (IFRS), 98200-000, Ibirubá, RS, Brasil. E-mail: plmarcos1@yahoo.com.br. Autor para correspondência.

"Departamento de Fitotecnia, Universidade Federal de Pelotas (UFPel), Pelotas, RS, Brasil.

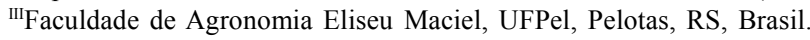


Com a expansão do sistema de plantio direto, a aveia preta ocupa hoje uma área de aproximadamente 2,5 milhões de hectares, fazendo parte de várias cadeias produtivas, tais como da soja, do milho e do fumo, sendo aproveitada como cultura de cobertura no inverno do Rio Grande do Sul, contribuindo com a sustentabilidade desses sistemas produtivos (MENEZES et al., 2007). A referida espécie também possui importância em outros países do Conesul da América do Sul (Brasil, Argentina, Chile e Uruguai), como planta forrageira (COMISSÃO BRASILEIRA DE PESQUISADEAVEIA, 2006).

No sistema de integração lavoura-pecuária, muitos agricultores do Sul do Brasil semeiam cultivares de aveia, imediatamente após a colheita das culturas de verão (soja e milho), entre os meses de março e maio. Nessas áreas, realizam pastoreio no inverno e colhem grãos do rebrote (COMISSÃO BRASILEIRA DE PESQUISADEAVEIA, 2006).

Após a colheita, um banco de sementes do solo (BSS) é formado a partir das sementes que se desprenderam naturalmente antes da colheita e das que foram perdidas durante esse processo. O manejo orientado para realização da ressemeadura natural vem sendo cada vez mais utilizado, visando a não necessitar de uma nova semeadura no ano seguinte.

As sementes que caem e permanecem dormentes após a disseminação formam os chamados "bancos de sementes do solo", os quais são reservas de sementes viáveis que podem estar localizadas tanto na superfície como em diferentes profundidades (LACERDA et al., 2005). A variabilidade e a biodiversidade botânica de determinado local depende das sementes presentes no solo, em determinado momento, sendo obtidas através do balanço entre a entrada de novas sementes e as perdas por germinação, deterioração, parasitismo, predação e transporte (CARMONA, 1992; MAIA \& MAIA, 2008).

A determinação do tamanho e da composição do banco de sementes do solo constituise pelo conhecimento essencial para o entendimento das estratégias regenerativas, implicadas na dinâmica sucessional dos agroecossistemas (MEDEIROS, 2000). No entanto, para a cultura da aveia preta, que possui sementes com capacidade de permanecerem viáveis de um cultivo para outro, ainda não foram realizados estudos quanto à formação de um banco de sementes no solo. Dessa forma, o objetivo do trabalho foi avaliar o número de sementes de aveia preta resultantes de dois sistemas de manejo, colheita e ressemeadura natural, que contribuirão na formação do banco de sementes do solo.

\section{MATERIAL E MÉTODOS}

O trabalho foi realizado em uma propriedade rural localizada no município de Jari - RS, na região ecofisiográfica denominada Planalto, altitude de $441 \mathrm{~m}$, latitude $29^{\circ} 17^{\prime} 29^{\prime \prime}$ e longitude $54^{\circ} 13^{\prime} 26^{\prime \prime}$ e, de acordo com MORENO (1961), o clima é do tipo Cfa 1, segundo a classificação de KÖEPPEN. A precipitação e temperatura médias anuais variando de 1.558 a $1.767 \mathrm{~mm}$ e 17,1 a $17,9^{\circ} \mathrm{C}$, respectivamente, caracterizando o clima subtropical, do ponto de vista térmico. O solo da área pertence à Unidade de Mapeamento Júlio de Castilhos e é classificado como Argissolo Vermelho-Amarelo Alumínico Alissólico (EMBRAPA, 1999).

Para a realização do trabalho, foi utilizada uma lavoura comercial em que o cultivo vem sendo realizado há três safras sob sistema de "plantio direto" com a seguinte sequência de culturas: soja no verão e aveia preta no inverno. A área utilizada foi submetida ao pastejo por bovinos, em uma lotação de 0,8 animais $\mathrm{ha}^{-1}$ de aproximadamente $350 \mathrm{~kg}(0,62 \mathrm{UA})$, os quais permaneceram na área por aproximadamente 60 dias. No ano de avaliação do banco de sementes, os animais foram colocados na área no início da segunda quinzena de julho de 2009. No primeiro e segundo anos de cultivo, foi realizada a colheita da aveia preta na área e, no terceiro ano, foi realizada a colheita em uma área e em outra não (Tabela 1). A correção do $\mathrm{pH}$ e adubação foram feitas através do resultado de análise de solo em concordância com tabelas da SOCIEDADE BRASILEIRADE PESQUISADE AVEIA(2004), sendo realizada adubação somente na cultura da soja.

O experimento foi constituído de dois sistemas de manejos na aveia preta: 1 - colheita das sementes com máquina automotriz e, 2 - ressemeadura natural (sem a colheita). A coleta das amostras de solo foram realizadas em novembro de 2009. O tamanho do banco de sementes foi estimado através da coleta de 50 amostras em cada sistema, em um espaçamento de $10 \mathrm{~m} \times 20 \mathrm{~m}$ ( $10 \mathrm{~m}$ entre amostras e $20 \mathrm{~m}$ entre linhas, com 10 amostras por linha), utilizando-se um amostrador de diâmetro de $0,05 \mathrm{~m}$ e profundidade de $0,1 \mathrm{~m}$.

Posteriormente, as amostras foram levadas ao Laboratório Didático da Faculdade de Agronomia Eliseu Maciel (FAEM/UFPel) para serem secas e processadas. A secagem foi realizada em estufa com circulação de ar a $30^{\circ} \mathrm{C} \mathrm{e}$, em seguida, as amostras foram destorroadas com rolos e procedeu-se à contagem do número de sementes em cada amostra, contabilizando as sementes soltas e as presas nas panículas.

Para estimar a produtividade de sementes foi computado o peso de 1000 sementes utilizando-se oito repetições de 100 sementes (BRASIL, 2009), que 
Tabela 1 - Sequência temporal de cultivos e finalidades na área experimental (sistemas de manejo estudados * Primeiro manejo e ** Segundo manejo) e número de sementes encontrado, sementes $\mathrm{m}^{-2} \mathrm{e} \mathrm{ha}^{-1}$, peso de 1000 sementes $(23,18 \mathrm{~g})$, peso de sementes ha ${ }^{-1}$, conforme o número de sementes encontrado, número de parcelas em que o número de semente foi encontrado e rendimento ha ${ }^{-1}$, conforme o número de parcelas encontradas com o número de sementes. Jari, RS, Novembro de 2009.

\begin{tabular}{|c|c|c|c|c|c|}
\hline & & \multicolumn{4}{|c|}{ Sequência temporal de cultivos e finalidades na área } \\
\hline \multicolumn{2}{|c|}{ Estação/ano } & \multicolumn{3}{|c|}{ Cultura/finalidade } & \\
\hline \multicolumn{2}{|c|}{ Verão/2007 } & \multicolumn{3}{|c|}{ Soja/grão } & \\
\hline Inverno & & \multicolumn{3}{|c|}{ Aveia preta/colheita } & \\
\hline Verão/2 & & \multicolumn{3}{|c|}{ Soja/grão } & \\
\hline Inverno & & \multicolumn{3}{|c|}{ Aveia preta/colheita } & \\
\hline Verão/2 & & \multicolumn{3}{|c|}{ Soja/grão } & \\
\hline \multicolumn{2}{|c|}{ Inverno/2009 } & \multicolumn{3}{|c|}{ Aveia preta/colheita* } & \\
\hline & & \multicolumn{4}{|c|}{ Aveia preta/ressemeadura natural ${ }^{* *}$} \\
\hline Sementes encontradas & Sementes $\mathrm{m}^{-2}$ & Sementes $\mathrm{ha}^{-1}$ & Peso kg ha ${ }^{-1}$ & Parcelas & Rendimento \\
\hline 0 & 0 & 0 & 0 & 11 & 0 \\
\hline 1 & 510 & 5102041 & 118 & 13 & 1538 \\
\hline 2 & 1020 & 10204082 & 236 & 4 & 946 \\
\hline 3 & 1530 & 15306122 & 354 & 8 & 2839 \\
\hline 4 & 2040 & 20408163 & 473 & 7 & 3312 \\
\hline 5 & 2551 & 25510204 & 591 & 1 & 591 \\
\hline 7 & 3571 & 35714286 & 828 & 1 & 828 \\
\hline 9 & 4591 & 45918367 & 1064 & 1 & 1064 \\
\hline 10 & 5102 & 51020408 & 1183 & 1 & 1183 \\
\hline 13 & 6632 & 66326531 & 1538 & 1 & 1538 \\
\hline 14 & 7142 & 71428571 & 1656 & 1 & 1656 \\
\hline \multirow[t]{3}{*}{16} & 8163 & 81632653 & 1893 & 1 & 1893 \\
\hline & & & & 50 & 17392 \\
\hline & & & & Total & 347 \\
\hline 2 & 1020 & 10204082 & 236 & 1 & 236 \\
\hline 3 & 1530 & 15306122 & 354 & 2 & 709 \\
\hline 4 & 2040 & 20408163 & 473 & 3 & 1419 \\
\hline 5 & 2551 & 25510204 & 591 & 2 & 1183 \\
\hline 6 & 3061 & 30612245 & 709 & 4 & 2839 \\
\hline 7 & 3571 & 35714286 & 828 & 2 & 1656 \\
\hline 8 & 4081 & 40816327 & 946 & 1 & 946 \\
\hline 9 & 4591 & 45918367 & 1064 & 5 & 5324 \\
\hline 10 & 5102 & 51020408 & 1183 & 8 & 9465 \\
\hline 11 & 5612 & 56122449 & 1301 & 4 & 5205 \\
\hline 12 & 6122 & 61224490 & 1419 & 4 & 5679 \\
\hline 13 & 6632 & 66326531 & 1538 & 1 & 1538 \\
\hline 14 & 7142 & 71428571 & 1656 & 3 & 4969 \\
\hline 15 & 7653 & 76530612 & 1774 & 4 & 7098 \\
\hline 16 & 8163 & 81632653 & 1893 & 3 & 5679 \\
\hline 22 & 11224 & 112244898 & 2602 & 1 & 2602 \\
\hline 26 & 13265 & 132653061 & 3076 & 1 & 3076 \\
\hline \multirow[t]{3}{*}{33} & 16836 & 168367347 & 3904 & 1 & 3904 \\
\hline & & & & 50 & 63535 \\
\hline & & & & Total & 1270 \\
\hline
\end{tabular}

foram obtidas da área colhida. O número de sementes em cada parcela amostrada foi transformado para $\mathrm{m}^{2}$, obtendo-se o peso por ha ${ }^{-1}$ através da multiplicação do número de vezes que esse valor foi repetido nas parcelas e, por fim, dividindo pelo número total de parcelas.

Posteriormente, as amostras foram depositadas em bandejas de $0,12 \times 0,20 \mathrm{~m}$, formando 
camadas de $3 \mathrm{~cm}$, que foram irrigadas quando necessário (irrigação utilizando aproximadamente $60 \%$ da capacidade de campo), para que as sementes viáveis pudessem germinar. A contagem das plântulas emergidas foi realizada quando o coleóptilo e plúmula estavam acima da superfície do solo. Com o intuito de superar possíveis mecanismos de dormência nas sementes, o solo foi revolvido a cada três semanas e realizada uma nova irrigação, constituindo um novo ciclo de germinação (MEDEIROS \& STEINER, 2002; MAIA \& MAIA, 2008). Foram realizados quatro ciclos de germinação para exaurir o banco de sementes. Dessa forma, quantificou-se a fração viável do banco de sementes, com capacidade de estabelecer plântulas normais.

As quantidades de sementes contidas na amostra e sementes germinadas foram extrapoladas para a unidade de sementes por metro quadrado na área experimental. $\mathrm{O}$ tratamento estatístico utilizado foi através de normalidade e transformação dos dados a $v y+0,5$ e teste $F$, após foi utilizada estatística descritiva, através de histogramas e mapas geoestatísticos.

\section{RESULTADOS E DISCUSSÃO}

A análise estatística dos dados demonstrou valor mais elevado para as variáveis número de sementes, sementes nas panículas e número de plântulas na área com ressemeadura natural. Nas figuras $1 \mathrm{~A}$ e B, assim como na tabela 1, estão expostos os dados da quantidade de sementes encontradas em cada parcela. Verifica-se que, na área em que se realizou a colheita, ocorreu um número elevado de parcelas sem semente, precisamente 11 . Na área com ressemeadura natural, o número mínimo de sementes observado foi de duas por parcela, no entanto, em uma parcela encontrou-se a quantidade de 33 sementes.

O elevado número de amostras sem ou com apenas uma semente, como ocorreu na área onde se realizou a colheita, não permite considerar a condição de ressemeadura ou a possibilidade de cobertura do solo ou formação de pastagem, pois o elevado número de parcelas com nenhuma ou apenas uma semente pode resultar em desuniformidade na área.

O comportamento da produtividade na área também pode ser visualizado pelos dados da tabela 1 , os quais estão extrapolados para a quantidade produzida por hectare. O rendimento obtido pelo produtor na área colhida foi de $840 \mathrm{~kg} \mathrm{ha}^{-1}$ de sementes limpas e secas e o rendimento potencial, segundo dados da tabela 1 , foi de $1270 \mathrm{~kg} \mathrm{ha}^{-1}$. Os dados demonstram que permanecem no solo $350 \mathrm{~kg} \mathrm{ha}^{-1}$, resultando em uma produção de $920 \mathrm{~kg} \mathrm{ha}^{-1}$, uma diferença de $80 \mathrm{~kg} \mathrm{ha}^{-1}$ da obtida pelo produtor. Uma das possíveis causas da diferença entre os valores são as sementes de aveia preta que ficaram no solo em anos anteriores, pois, mesmo na área com colheita, permanecem aproximadamente $350 \mathrm{~kg}$ de semente. A produtividade alcançada, considerada média-baixa, está associada ao pastejo realizado, pois reduziu a produção e o peso hectolitro em relação às áreas não pastejadas (COMISSÃO BRASILEIRA DE PESQUISA DEAVEIA, 2006).

$\mathrm{Na}$ área em que foi realizada a colheita, não se observaram sementes presas às panículas, no entanto, na área com ressemeadura natural, foi constatado que $6 \%$ das sementes ficaram presas às panículas. Esse resultado indica que algumas das sementes ficaram ligadas às plantas que, posteriormente, tombaram no solo. Mesmo assim, grande parte das sementes se solta das panículas, o que pode ser uma das causas da grande quantidade de sementes encontrada no solo, mesmo com a realização da colheita.

A diferença na quantidade de sementes nas panículas, entre as parcelas, na ressemeadura natural foi elevada (Figura 1C). A parcela 41 foi a que apresentou a maior porcentagem das sementes nas panículas (55\%), seguida pela parcela $39 \mathrm{com} 45 \%$ e a $31 \mathrm{com}$ $32 \%$. Algumas parcelas variaram de 10 a $20 \%$ de sementes presas e, em várias parcelas, não houve sementes presas nas panículas. Os resultados obtidos indicam que poucas sementes se encontravam nas plantas, confirmando que, na cultura da aveia preta, há uma grande debulha natural, indicando que, se a colheita não for realizada na época ideal, ocorrerá perda por debulha natural.

Para demonstrar a distribuição das sementes nas áreas, foram confeccionados mapas geoestatísticos, apresentados na figura 2 (A) área colhida e (B) com ressemeadura natural, o que possibilita confirmar a heterogeneidade da distribuição de sementes na área, além de verificar as áreas que possivelmente ficariam sem cobertura. Basicamente, estão presentes seis áreas sem sementes, quatro menores compostas por apenas uma parcela sem semente $(1,2,3$ e 4$)$ e duas maiores, formadas por mais de duas parcelas (5 e 6). Nas áreas cinco e seis, observa-se uma sequência de parcelas sem sementes, o que pode ocasionar problemas nesses locais pela falta de cobertura do solo ou de pastagem. As áreas um, dois, três e quatro são compostas pelas parcelas de campo 1, 4, 16 e 30, respectivamente, a cinco, pelas parcelas 26, 27, 20 e 33, enquanto a composição da seis foi com as parcelas 38,39 e 40 .

A maior parte da área ficou com um número de 900 e 1800 semente $\mathrm{m}^{-2}$, valores acima da indicação 


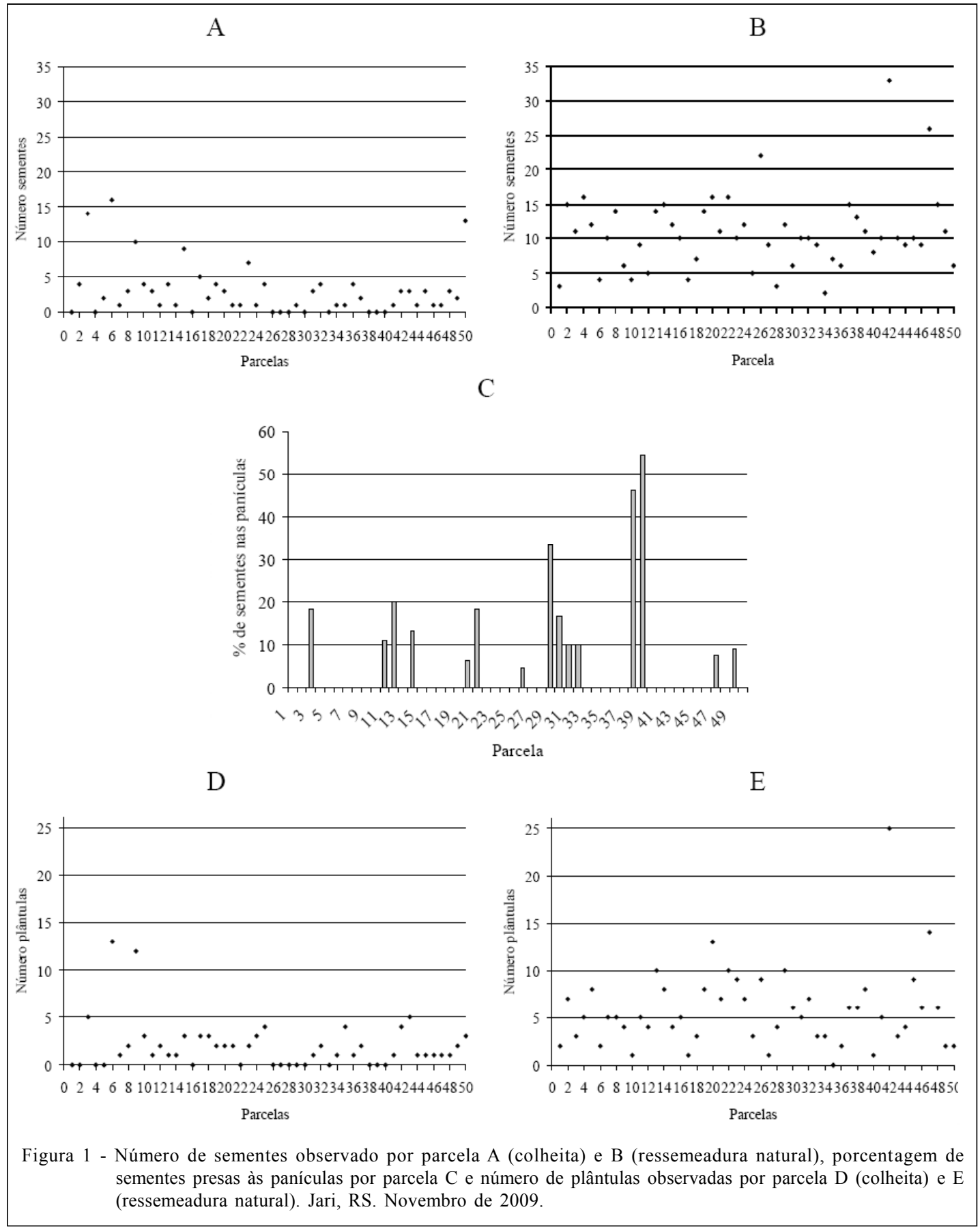

técnica para a cultura, que é de 200 a 300 sementes viáveis $\mathrm{m}^{-2}$ (COMISSÃO BRASILEIRA DE PESQUISA DE AVEIA, 2006). Resultado que deve ser levado em conta pelos produtores que utilizaram a área para cultivo do trigo no ano seguinte, pois possivelmente terão plantas de aveia provenientes das sementes do BSS.

$\mathrm{Na}$ área com ressemeadura natural, a quantidade de sementes $\mathrm{m}^{-2}$ foi elevada, variando de
1000 a 17000 , o que possivelmente possibilita a formação de um banco de sementes considerável. Na maior parte da área, contatou-se entre 5000 e 7000 sementes $\mathrm{m}^{-2}$, valor acima do número de sementes indicado para semeadura em condição normal (COMISSÃO BRASILEIRADE PESQUISADEAVEIA, 2006). 


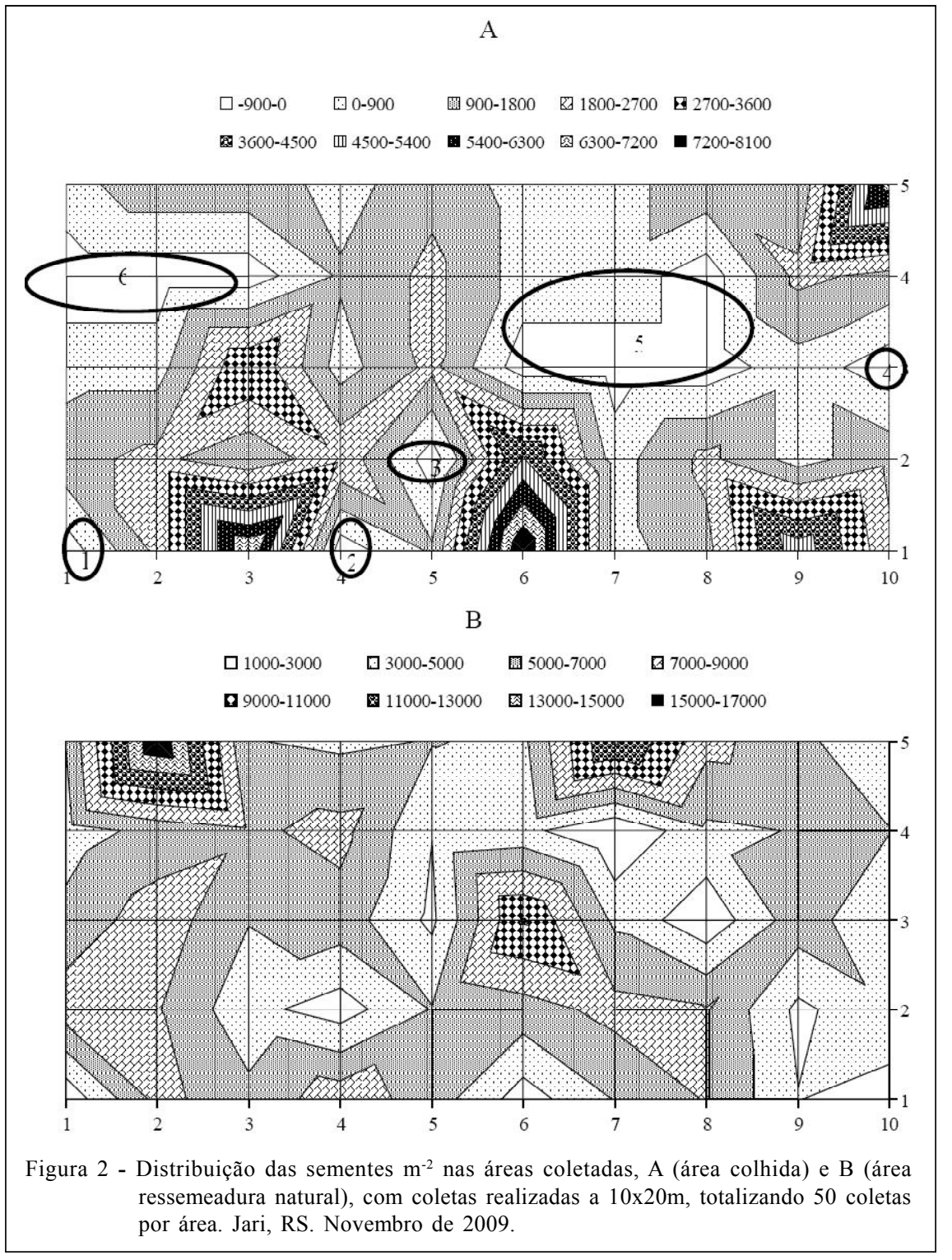

Os dados da emergência das plântulas nas parcelas (Figura 1D e E) demonstram que, na área com colheita, ocorreu um maior número de pontos sem plântulas do que sem sementes, indicando que as sementes encontradas na avaliação não formaram plântulas. O que é explicado pelo número de parcelas sem semente ser 11 e o sem plântulas ser 15 . Na área com ressemeadura natural, o número de plântulas emergidas também foi menor que o número de sementes contabilizadas. $\mathrm{Na}$ área com ressemeadura natural, também foi observada uma parcela sem a formação de plântula.

Resultados diferentes entre o número de sementes e plântulas são normais, pois as sementes presentes no solo ficam sujeitas à deterioração, parasitismo e predação (CARMONA, 1992; MAIA \& MAIA, 2008). Na área com colheita, em grande parte das parcelas houve emergência entre zero e quatro plântulas, enquanto, na ressemeadura, a maior parte das parcelas encontrava-se com valores entre uma e dez plântulas (Figura 1D e E).

O mapa do número de plântulas obtidas (Figura 3A e B) demonstra que ocorreu um aumento de áreas que possivelmente ficaram sem cobertura, constatando-se quatro áreas, das quais a primeira e a segunda são áreas menores e compostas por duas e três parcelas sem plântulas, respectivamente. No mapa de distribuição de sementes (Figura 2A), pode-se observar que a primeira área sem plântulas é formada por uma parcela sem semente e outra próxima com 


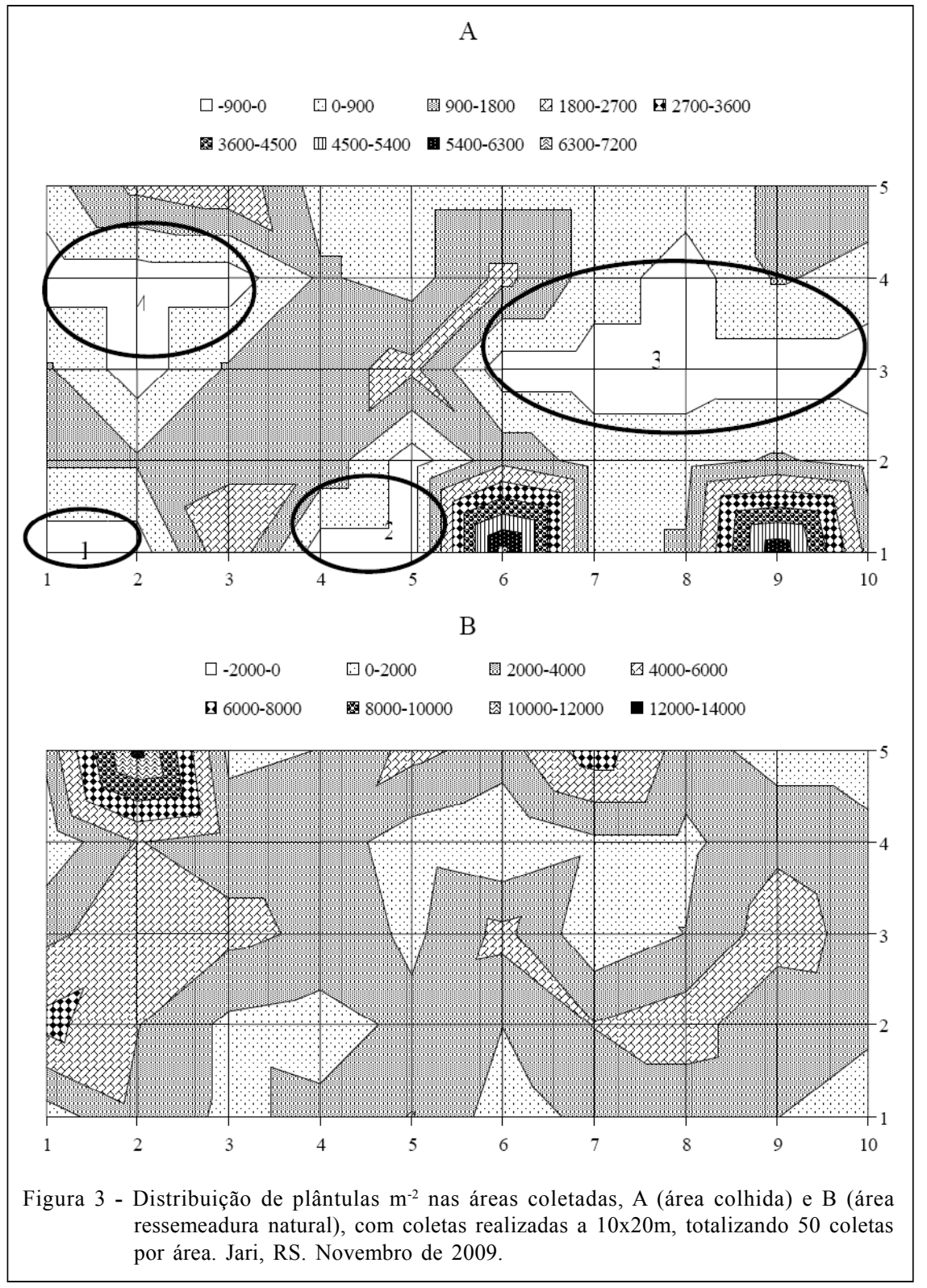

semente, mas sem emergência. Entretanto, a área dois foi composta por duas parcelas sem semente e uma com semente, mas sem a emergência de plântula.

O número de parcelas que compõem as áreas três e quatro foi maior. Aárea três ficou composta pelas áreas sem sementes, que são a quatro e a cinco (Figura 2A), juntamente com uma parcela com uma semente apenas no momento de contagem, porém esta não formou plântula, sabendo que a área três é formada pelas parcelas $26,27,28,29,30$ e 33 . A área quatro foi formada pelas parcelas $22,38,39 \mathrm{e} 40$ destas e a parcela 22 foi a única com semente. Observando o mapa, podese constatar um comportamento específico para determinadas áreas, pois as áreas sem plântulas são formadas por, no mínimo, duas parcelas. As áreas 1 e 2 são formadas por parcelas da extremidade da área coletada. Nas áreas 3 e 4, observa-se, no mínimo, quatro parcelas sem plântulas e ambas com pontos nas extremidades da área.

A área com ressemeadura natural se caracterizou sempre por amostras com sementes. Observou-se uma amostra que não originou plântulas, a parcela 35 (Figura 1E), no entanto, no mapa, essa falha não fica comprovada como sem plântulas, devido ao elevado número de plântulas das parcelas que a cercam. $\mathrm{Na}$ área colhida, a maior parte encontra-se entre 
zero e 1800 plântulas $\mathrm{m}^{-2}$. Na ressemeadura, o número de plântulas ficou em torno de 2000 e 4000 plântulas $\mathrm{m}^{-2}$. A colheita de aveia preta proporciona áreas sem sementes e, consequentemente, sem plântulas, o que ocasiona áreas sem cobertura do solo na safra seguinte. Isso pode gerar erosão, selamento superficial, aumento de plantas daninhas, maior perda de água por evaporação, como também perdas de nutrientes, pois um dos requisitos para garantir a eficiência desse sistema de "plantio direto" é a adequada cobertura do solo por espécies formadoras de palha (ANDREOTTI et al., 2008). Assim, a semeadura na área deve ser feita sempre que ocorrer a colheita.

Mesmo quando a área foi utilizada para o pastejo, uma grande quantidade de sementes foi encontrada no solo. Possivelmente, devido à retirada antecipada do gado, o que permitiu a formação de sementes nas plantas de aveia preta e a ressemeadura natural. Nessas áreas em que houve a formação e deposição de sementes no solo, pode ocorrer a germinação dessas sementes para formar a pastagem ou cobertura do solo na safra seguinte. Assim, as sementes que não germinam ficarão viáveis no solo (através da dormência) e formarão o banco de sementes de aveia preta na área (CARMONA, 1992).

\section{CONCLUSÃO}

A colheita e a ressemeadura natural possibilitam a presença de quantidades de sementes no solo por área superior à indicada para a semeadura. A colheita proporciona heterogeneidade no número de sementes no solo e em plantas na área. A ressemeadura natural resulta em uma grande quantidade de sementes no solo e formação de plântulas.

\section{REFERÊNCIAS}

ANDREOTTI, M. et al. Produtividade do milho safrinha e modificações químicas de um Latossolo em sistema plantio direto em função de espécies de cobertura após calagem superficial. Acta Scientiarum Agronomy, v.30, n.1, p.109-
115, 2008. Disponível em: <http://periodicos.uem.br/ojs/ index.php/ActaSciAgron/article/view/1158/632>. Acesso em: 20 mar. 2010. doi: 10.4025/actasciagron.v30i1.1158.

BRASIL. Ministério da Agricultura, Pecuária e Abastecimento. Regras para análise de sementes. Brasília: MAPA/ACS, 2009. 399p.

CARMONA, R. Problemática e manejo de bancos de sementes de invasoras em solos agrícolas. Planta Daninha, v.10, n.1, p.5-16, 1992.

COMISSÃO BRASILEIRA DE PESQUISA DE AVEIA. Indicações técnicas para cultura da aveia. Guarapuava: Fundação Agrária de Pesquisa Agropecuária, 2006. 82p.

EMBRAPA. Centro Nacional de Pesquisa de Solos Sistema Brasileiro de Classificação de Solos. Brasília: EMBRAPA Produção de Informações; EMBRAPA Solos, 1999. 412p.

LACERDA, A.L.S. et al. Levantamento do banco de sementes em dois sistemas de manejo de solo irrigados por pivô central. Planta Daninha, v.23, n.1, p.1-7, 2005. Disponível em: $<$ http://www.scielo.br/pdf/pd/v23n1/23922.pdf $>$. Acesso em: 02 de out. de 2010. doi: 10.1590/S0100-83582005000100001.

MAIA, F.C.; MAIA, M.S. A dinâmica das sementes no solo. Pelotas: Editora e Gráfica Universitária PREC-UFPEL. 2008. 88p.

MEDEIROS, R.B. Bancos de sementes no solo e dinâmica vegetacional. Reunião do Grupo Técnico em Forrageiras do Cone Sul - Zona Campos, v.18. p.62-87, 2000.

MEDEIROS, R.B.; STEINER, J.J. Influência de sistemas de rotação de sementes de gramíneas forrageiras temperadas na composição do banco de sementes invasoras no solo. Revista Brasileira de Sementes, v.24, n.1, p.118-128, 2002.

MENEZES, N.L. et al. Teste de condutividade elétrica em sementes de aveia preta. Revista Brasileira de Sementes, v.29, n.2, p.138-142, 2007. Disponível em: <http:// www.scielo.br/pdf/rbs/v29n2/v29n2a19.pdf >. Acesso em: 20 mar. 2010. doi: 10.1590/S0101-31222007000200019.

MORENO, J.A. Clima do Rio Grande do Sul. Porto Alegre: Secretaria de Agricultura. Diretoria de terras e colonização, seção de geografia, 1961. 43p.

SOCIEDADE BRASILEIRA DE CIÊNCIA DO SOLO. Comissão de Química e Fertilidade do Solo. Manual de adubação e calagem para os estados do Rio Grande do Sul e Santa Catarina/SBCS. 10.ed. Porto Alegre, 2004. 400p. 